\title{
Plant community impact on productivity: the interplay of community-level functional attributes, species, and environmental selection
}

Philipp Brun ${ }^{1}$, Cyrille Violle ${ }^{2}$, David Mouillot ${ }^{3}$, Nicolas Mouquet ${ }^{2}$, Brian Enquist ${ }^{4}$, François Munoz ${ }^{5}$, Tamara Munkemuller ${ }^{6}$, Annette Ostling ${ }^{7}$, Niklaus Zimmermann ${ }^{8}$, and Wilfried Thuiller ${ }^{9}$

${ }^{1}$ Swiss Federal Institute for Forest Snow and Landscape Research

${ }^{2} \mathrm{CNRS}$

${ }^{3}$ Université Montpellier-CNRS-IFREMER

${ }^{4}$ University of Arizona

${ }^{5}$ Université Grenoble Alpes

${ }^{6}$ Univ. Grenoble Alpes

${ }^{7}$ University of Michigan

${ }^{8}$ Swiss Federal Resarch Institute WSL

${ }^{9}$ Laboratoire d'Ecologie Alpine

July 5, 2021

\begin{abstract}
While the impact of biodiversity, notably functional diversity, on ecosystem productivity has been extensively studied, little is known about the effect of individual species. Here, we identified species of high importance for productivity (key species) in over 28,000 diverse grassland communities in the European Alps, and compared their effects with those of community-level measures of functional composition (weighted means, variances, skewness, and kurtosis). After accounting for the environment, the five most important key species jointly explained more deviance than all statistics of functional composition. Key species were generally tall with high specific leaf areas. By dividing the observations according to distinct habitats, the explanatory power of all non-environmental predictors increased considerably, and the relationships between functional composition and productivity varied systematically, presumably because of changing interactions and trade-offs between traits. Our results advocate for a better consideration of species' individual effects on ecosystem functioning in complement to community-level measures.
\end{abstract}

\section{Hosted file}

manuscript_v3.pdf available at https://authorea.com/users/423862/articles/529089-plantcommunity-impact-on-productivity-the-interplay-of-community-level-functional-attributesspecies-and-environmental-selection 